Journal of Clinical Investigation

Vol. 41, No. 3, 1962

\title{
THE EFFECTS OF PHOSPHOPROTEINS ON ACID BALANCE IN NORMAL SUBECTS *
}

\author{
By EDWARD J. LENNON, $\nmid$ JACOB LEMANN, JR. AND ARNOLD S. RELMAN with \\ THE TECH NICAL ASSISTANCE OF HELEN P. CONNORS \\ (From the Evans Memorial Department of Clinical Research, Massachusetts Memorial Hos- \\ pitals, and the Department of Medicine, Boston University School of Medicine, \\ Boston, Mass.)
}

(Submitted for publication September 11, 1961 ; accepted November 6, 1961)

Identification and measurement of the dietary sources of fixed endogenous acid have been hampered by the chemical complexity of naturally occurring foods. Recent studies from this laboratory (1) have demonstrated the feasibility of identifying and quantitating the sources of fixed acid production when a chemically defined, synthetic diet is utilized and body composition remains approximately constant. With the special diet used in those studies, the processes resulting in net endogenous acid production in the steady state were identified as: $a$ ) the release of acid during the oxidation of neutral sulfur to inorganic sulfate, and $b$ ) the net production of organic acids from neutral foodstuffs. In addition, $c$ ) the data suggested that a third source of acid was related to the phosphorus content of the dietary protein, and it was proposed that acid was released during the oxidation of the cations neutralizing phosphate esters, or during the hydrolysis of phosphate diesters in the protein, or both. However, the amount of organic phosphorus in the basic diet was relatively small and analysis of its contributions to acid production was therefore limited.

Accordingly, in the present experiments the postulated role of phosphorus was tested more critically by the administration of extra loads of the purified soy phosphoprotein used in the basic diet. The effects were compared with those of feeding equivalent loads of a more complex natural protein (contained in cooked ground beefsteak). The data to be presented support our previous conclusions that a predictable amount of

\footnotetext{
* Supported by U.S. Public Health Service Grant A-3140. Submitted in honor of Chester S. Keefer, M.D., and the Golden Anniversary of the Evans Memorial Department of Clinical Research, Boston, Mass.

+ During tenure as a Trainee of the National Institute of Arthritis and Metabolic Diseases. Present address: Milwaukee County Hospital, Milwaukee 13, Wis.
}

acid production is associated with the metabolism of phosphorus in the purified protein used in the basic diet. On the other hand, the net acidifying effect of the meat could be completely accounted for by the measured increase in the oxidation of sulfur and the production of organic acids without considering the phosphorus content. This suggests either that the phosphate residues in the meat were in a form that does not release acid or that the acid released was neutralized by the simultaneous production of an equivalent quantity of alkali that might be expected to have derived from the meat. Taken together, the results of these studies are consistent with the view that the amount of acid produced in association with the metabolism of organic phosphorus depends upon the chemical form of the phosphate residues. Accurate, independent assessment of endogenous acid production is valid, and measurement of the net external acid balance possible, only when purified, well characterized food sources are used.

\section{METHODS}

Eight balance studies of 12 to 17 days' duration were carried out in 5 healthy, ambulatory, male medical students. Each study began with a 2-day period of adaptation to the diet. There followed a control period of 3 to 7 days, an experimental period lasting 3 days, and a recovery period of 5 to 7 days. During the experimental period in four studies the subjects were fed an additional load of soy phosphoprotein ( $1.5 \mathrm{~g}$ per $\mathrm{kg}$ per day). In the other four studies the subjects were fed an equivalent amount of nitrogen in the form of ground beefsteak $(6 \mathrm{~g}$ of meat per $\mathrm{kg}$ per day). The extra protein nitrogen load in both groups was approximately $0.2 \mathrm{~g}$ per $\mathrm{kg}$ per day.

The basic liquid formula diet was identical with that previously described (1). The purified soy phosphoprotein used as the sole source of nitrogen (sometimes hereinafter referred to by the manufacturer's name, "J-protein") was virtually free of inorganic cations and anions 


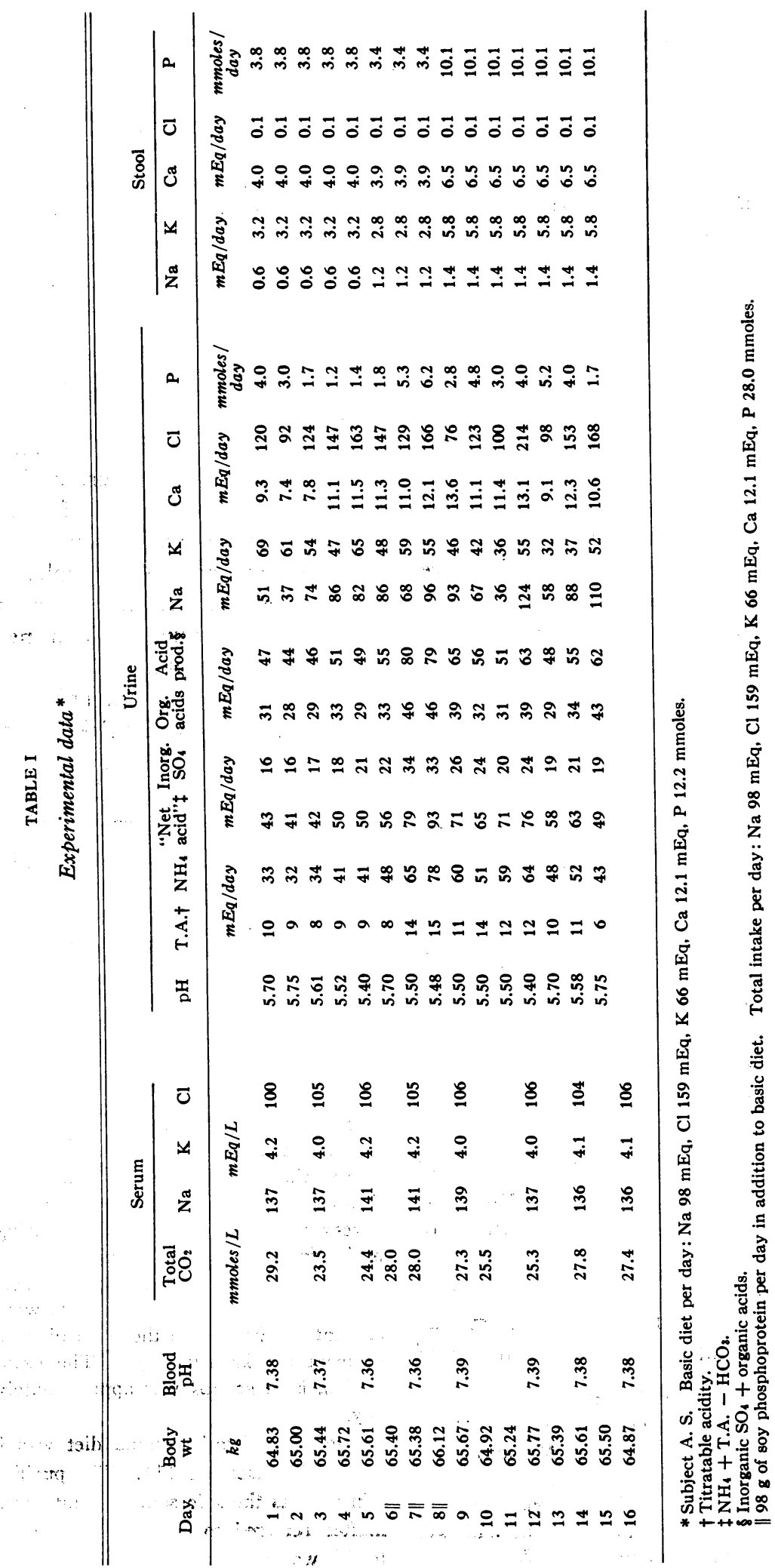


PHOSPHOPROTEIN AND ACID BALANCE

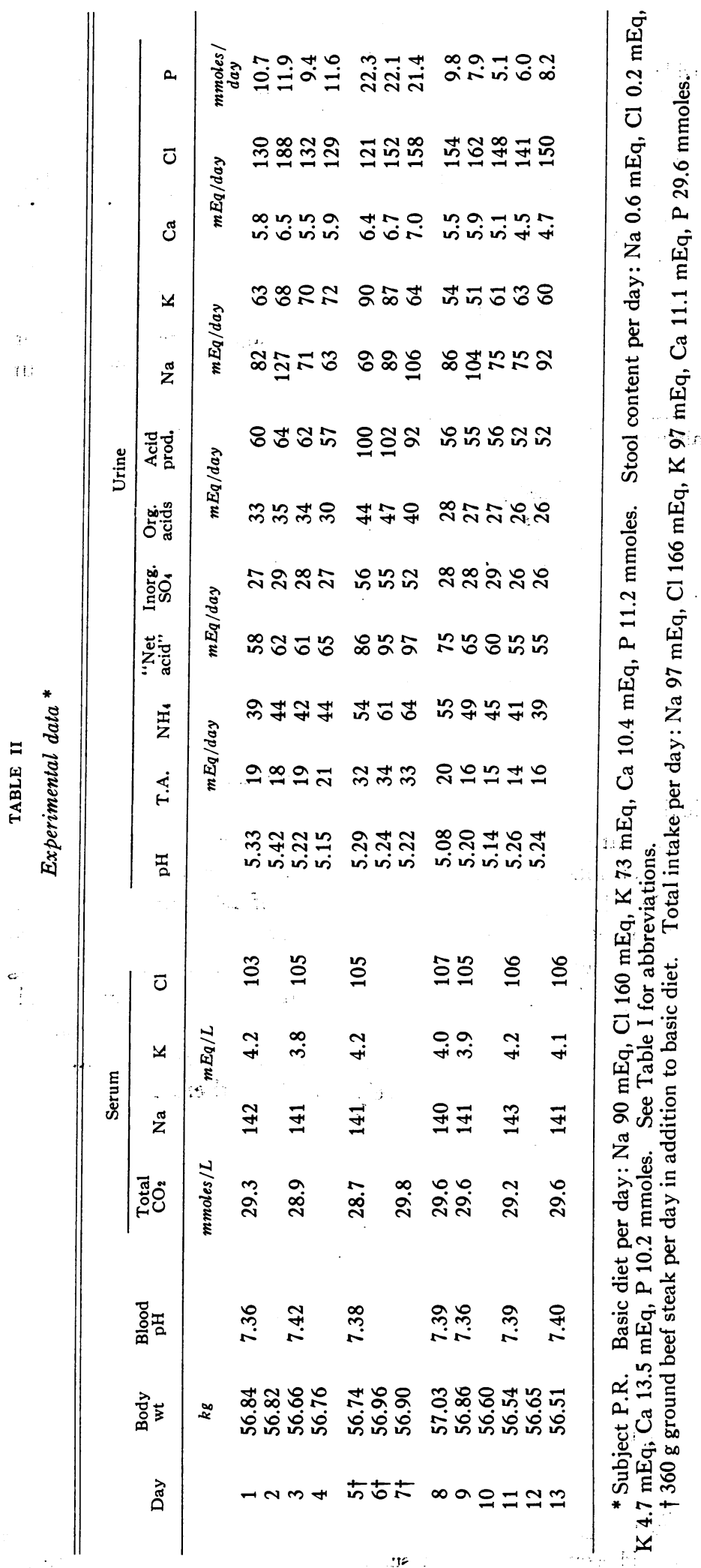


other than phosphate. ${ }^{1}$ Because alkali was required to disperse this protein, and because calcium and magnesium were not otherwise provided in the basic diet, an equimolar mixture of $\mathrm{Ca}(\mathrm{OH})_{2}$ and $\mathrm{Mg}(\mathrm{OH})_{2}$ was added. This provided milliequivalents of alkali equal to 1.8 times the millimoles of phosphorus in the diet protein. As discussed in a previous study (1), this quantity of alkali appeared approximately to neutralize that fraction of acid production from the basic diet not measured as urinary sulfate plus organic acids (and therefore presumed to be associated with the metabolism of the dietary phosphorus). Although the basic diet, with this quantity of alkali, was maintained constant throughout each balance study, no additional alkali was added to the extra soy protein or meat fed during the loading periods.

In two of the studies with meat the basic diet was sodium-free; in the remaining six balances the basic diet contained 1.5 mmoles of $\mathrm{NaCl}$ per $\mathrm{kg}$ per day; 1.0 mmoles per $\mathrm{kg}$ per day of $\mathrm{KCl}$ was added to all diets.

Details of the balance technique used in this laboratory and references to most of the analytical methods have already been published $(1,2)$. Titratable acid and organic acids in the urine were measured at $37^{\circ} \mathrm{C}$ with a Radiometer automatic titrator. Blood $\mathrm{pH}$ was determined with the Astrup capillary glass electrode at $37^{\circ} \mathrm{C}$. In a few balances, urinary uric acid was determined by a phosphotungstic acid method.

\section{RESULTS}

Complete analytical data from one subject given a soy protein load are shown in Table I; similar data for a subject loaded with beefsteak are presented in Table II. Figures 1 and 2 present some pertinent analytical and derived data from two other subjects loaded with soy phosphoprotein and meat, respectively.

A. Control observations. During control periods body weight and all of the measured constituents of plasma and urine remained relatively constant. Stools were small and infrequent and had a low content of electrolytes. With but few exceptions there were no significant positive or negative balances of any of these constituents.

In confirmation of previous observations in the steady state (1), it was noted that the net excretion of acid in the urine (titratable acid + ammonium - bicarbonate) was closely matched by the simultaneous endogenous production of acid as measured by the sum of the urine inorganic sulfate plus organic acids. ${ }^{2}$

\footnotetext{
$1 \mathrm{~J}$-protein-100, kindly made available by the J. R. Short Milling Company, Chicago, Ill.

2 When no inorganic alkali was added to the basic diet in previous experiments, acid excretion exceeded sulfate
}

In the lower half of Figures 1 and 2 the net external acid balance is plotted in the manner conventionally used for inorganic constituents. Acid production (inorganic sulfate + organic acid) is plotted downward from the zero axis. Net acid excretion is plotted upward from the heavy line indicating acid production. Thus, clear areas below the zero axis indicate positive acid balance, while extensions of the shaded area above the zero line define negative acid balance. Although there were minor daily fluctuations, it is apparent from these figures and from the data in Tables I and II that the subjects were in approximately zero net acid balance during the control periods. All eight balances considered, the mean per cent difference between the cumulative acid production and acid excretion [(production - excretion)/production] was $+1.8 \pm 6.4$ (SD) per cent.

B. Effects of soy phosphoroprotein loading. As shown in Table I and Figure 1, administration of extra soy protein was followed by an increase in the excretion of ammonium and titratable acid. Net acid excretion reached a maximum value almost double that of the control on the third and final day of loading. This gradually diminished during the recovery period, returning to baseline values by the end of the study. The $\mathrm{pH}$ of 24-hour urine specimens remained essentially unchanged. Serum $\mathrm{CO}_{2}$ content also showed no significant change. Urinary inorganic sulfate and organic acids increased, but the changes were smaller and less sustained than those in acid excretion. In the subject of Table I, as in the others fed soy protein, phosphorus excretion increased only slightly, if at all. Stool calcium, phosphorus, and potassium excretion increased slightly during the recovery period. There were no consistent or significant changes in the urinary excretion or the net balance of sodium, potassium, or chloride.

In all four subjects loaded with J-protein the pattern of response was quite similar in all respects to that described above. Despite approxi-

plus organic acids by an amount in milliequivalents approximately equal to 1.8 times the millimoles of protein phosphorus. In the present studies, in which an equivalent amount of alkali was added as calcium and magnesium hydroxide, it would be expected that this discrepancy would be eliminated. 


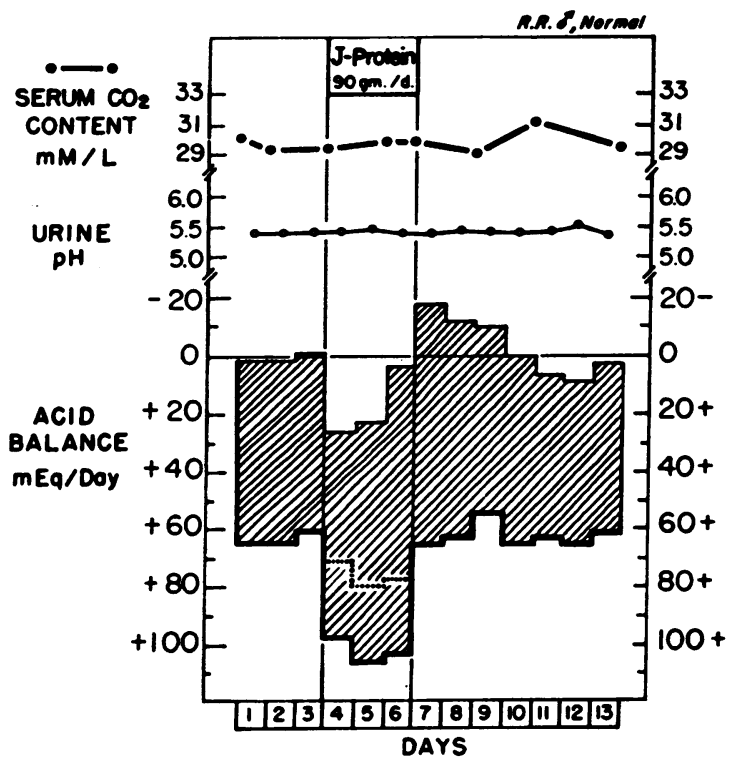

Fig. 1. Net external acid balance, Serum $\mathrm{CO}_{2}$ CONTENT, AND URINE PH IN A SUBJECT GIVEN A SUPPLEMENT OF J-PROTEIN FOR 3 DAYS. In the construction of the acid balance, total acid production is plotted downward from the zero line, and net acid excretion in the urine is plotted as a hatched column back up from the heavy line indicating production. Production is calculated (except during the loading period) as urinary sulfate + organic acids; excretion is urine ammonium + titratable acid - bicarbonate. During the loading period acid derived from the fed phosphorus is included in the calculation of total production. This increment is defined by the distance between the heavy line indicating total production and the dotted line parallel to it. See text for further details.

mately twofold increase in acid excretion, in no instance was there a detectable reduction in serum $\mathrm{CO}_{2}$ content. In each study the increment in the excretion of organic acids plus urinary sulfate was significantly less than that in acid excretion. In the upper half of Table III the total increment in acid excretion during and after the phosphoprotein load is compared with the total increase in the excretion of inorganic sulfate plus organic acids. These quantities were calculated by substracting the mean control values in each case from the daily observed values, until both production and excretion had returned to their original baselines. It is evident from Table III that in each of the four subjects fed soy protein the total increase in acid excretion considerably exceeded the total increase in sulfate plus organic acids. The increase in acid excretion ranged from 96 to $231 \mathrm{mEq}$, while the increase in the excretion of sulfate plus organic acids was only 37 to $144 \mathrm{mEq}$. The mean per cent difference was $121 \pm 44$ (SD) per cent.

C. Effects of loading with beefsteak. As shown in Table II and Figure 2, feeding of the beefsteak was also followed by an increase in the excretion of ammonium and titratable acid. In the study summarized in the table the total excretion of acid reached a peak of $97 \mathrm{mEq}$ per day on the third and final day of loading, representing an increase of more than 50 per cent above control. Acid excretion gradually returned to control levels by the second or third day of recovery. As with phosphoprotein loading, there was no significant change in serum $\mathrm{CO}_{2}$ content or urine $\mathrm{pH}$. The urinary excretion of inorganic sulfate and organic acids rose promptly with the feeding of meat and dropped back to control levels on the first day of recovery. In contrast to the results with the soy protein, the total increment in the excretion of inorganic sulfate and organic acids after meat feeding was virtually equal to the total increment in acid excretion. Urinary phosphorus excretion approximately doubled during the period of loading, and there was also a slight increase in potassium excretion, reflecting the increased intake. Sodium and chloride excretion were not discernibly affected. Because of small and infrequent stools no attempt was made in this study to divide the scanty fecal electrolyte excretion into separate periods.

TABLE III

Comparison of total increase in acid excretion with total increase in excretion of inorganic sulfate and organic acids for subjects fed soy protein and meat loads

\begin{tabular}{|c|c|c|c|}
\hline Subject & $\begin{array}{c}\text { A } \\
\text { Total } \\
\text { increase } \\
\text { in acid } \\
\text { excretion }\end{array}$ & $\begin{array}{c}\text { B } \\
\text { Total } \\
\text { increase } \\
\text { in SO4t } \\
\text { org. acids }\end{array}$ & $\begin{array}{c}\text { Difference } \\
\left(\frac{B-A}{B} \times 100\right)\end{array}$ \\
\hline Soy protein & $m E q$ & $m E q$ & $\%$ \\
\hline R.R. & 96 & 37 & -160 \\
\hline P.R. & 150 & 69 & -117 \\
\hline F.G. & 204 & 83 & -146 \\
\hline \multirow[t]{2}{*}{ A.S. } & 231 & 144 & -60 \\
\hline & \multicolumn{2}{|r|}{ Mean } & $-121 \pm 44$ \\
\hline \multicolumn{4}{|l|}{ Beefsteak } \\
\hline F.G. & 152 & 137 & -11 \\
\hline P.R. & 107 & 113 & +5 \\
\hline R.R. & 127 & 135 & +6 \\
\hline \multirow[t]{2}{*}{ G.S. } & 106 & 129 & +18 \\
\hline & \multicolumn{2}{|r|}{ Mean } & $+4.5 \pm 12$ \\
\hline
\end{tabular}




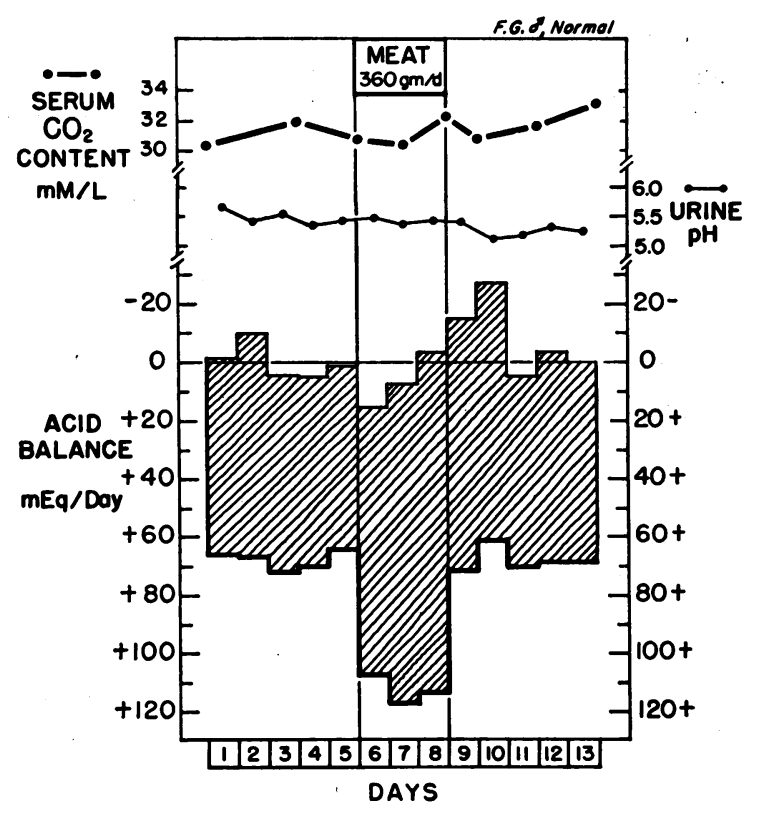

Fig. 2. Net external acid balance, Serum $\mathrm{CO}_{2}$ CONTENT, AND URINE PH IN A SUBJECT GIVEN A SUPPLEMENT OF MEAT. The acid balance is constructed in the same manner as in Figure 1, except that urine inorganic sulfate and organic acids are taken to be the sole sources of acid production throughout the study. See text for further details.

In the other three subjects the pattern of response was almost identical. In each instance acid excretion increased by 50 to 100 per cent without detectable change in serum $\mathrm{CO}_{2}$ content or urine $\mathrm{pH}$. There was a prompt increase in the excretion of sulfate and organic acids, limited to a period of loading, which closely matched the total increment in acid excretion. Restriction of sodium in the diet of two subjects did not affect this pattern, and the feeding of meat produced no significant change in the low control rates of sodium excretion. In two balances in which it was possible to divide stools into periods, there was a slight increase in fecal excretion of calcium, potassium, and phosphate during the loading or recovery periods.

In the lower half of Table III the total increments in acid excretion during and after meat feeding are compared with the total increase in the excretion of inorganic sulfate plus organic acids. These were calculated in the manner already described. It is apparent from the table, in contrast to the soy protein experiments shown in the upper half, that there was no significant or consistent difference between these quantities for the beefsteak experiments. The mean per cent difference between acid excretion and the sum of sulfate and organic acids was only $4.5 \pm 12$ (SD per cent.

\section{DISCUSSION}

The most striking finding in the four studies with the purified soy phosphoprotein was the large discrepancy between the total increase in acid excretion and the total increase in urinary inorganic sulfate plus organic acids (Table III). Previous experience (1), as well as the observations in the control periods in all of the present balances, indicates that with this balance technique discrepancies of this magnitude between acid excretion and the total measured production of fixed endogenous acid are not to be expected. The most reasonable conclusion to be drawn is that the extra phosphoprotein provided a third source of endogenous acid production in addition to the oxidation of sulfur to sulfate and the production of organic acids. If this third source of acid is assumed to be related to the phosphorus content of the phosphoprotein, the discrepancies noted above can be satisfactorily explained. The total load of extra organic phosphorus ranged from 43 to 53 mmoles, whereas the absolute discrepancies between acid excretion and the measured sources of production (sulfate + organic acids) ranged from 59 to $121 \mathrm{mEq}$. If the discrepancy in each case is divided by the extra phosphorus fed, the apparent acid derived per mmole of phosphorus ranges from 1.4 to $2.3 \mathrm{mEq}$ (mean, $1.9 \pm 0.3$ ). This calculation therefore is consistent with our previous conclusions that: $a$ ) endogenous acid production is associated with the metabolism of phosphorus in the purified soy phosphoprotein used in these studies, and $b$ ) the acid so released appears to approximate the theoretical amount to be expected from the hydrolysis of the organic phosphate residues in the protein and from the metabolism of the combustible cations associated with these residues. A more detailed discussion of this subject is given elsewhere $(1,3)$, but in the following paragraphs a brief attempt will be made to summarize the relevant considerations dealing with the role of organic phosphate in endogenous acid formation. 
Although it has been generally assumed that the metabolism of all organic phosphorus in the diet gives rise to acid, it has been pointed out by Christensen (4) and by Hunt (5) that the phosphorus present in natural foods as inorganic salts of orthophosphate monoesters should not be expected to yield acid. This is demonstrated by the following equation in which the inorganic cation neutralizing the orthophosphate residue in a protein is assumed to be all $\mathrm{K}^{+}$:

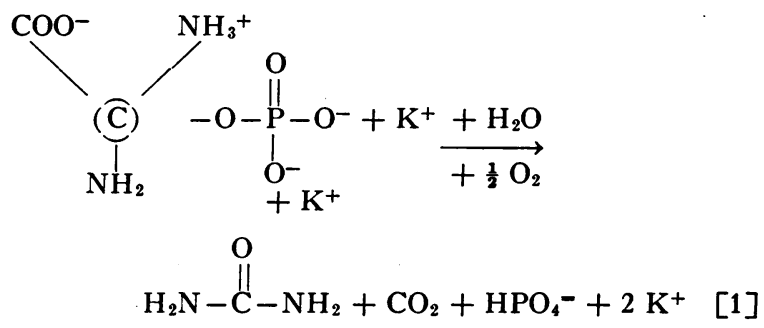

The problem is more complex than this, however, because Perlmann (6) has shown that natural phosphoproteins probably also contain diester and pyrophosphate structures as well as orthophosphate monoesters. Furthermore, diester structures are, of course, known to occur in phospholipids and nucleic acids and other compounds abundant in natural foods. In their natural state, neutralized at least in part by inorganic cations, these various forms of phosphorus would have differing effects on net acid production, and hence calculation of the latter quantity would require that the nature of the phosphate linkages be known in detail. Although such information is not available for the soy protein used in these studies or for most other phosphoproteins, this difficulty is eliminated by the use of the protein in its isoelectric form, free of all inorganic cations. This is explained by the following three reactions which schematically show the hydrolysis and combustion of an isoelectric phosphoprotein containing each of the three possible types of phosphate residues:

Orthophosphate monoester

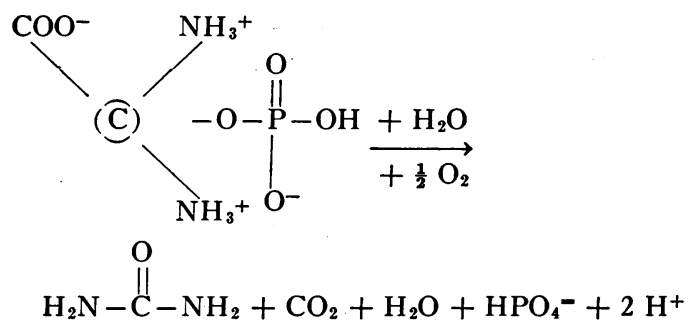

Pyrophosphate ester

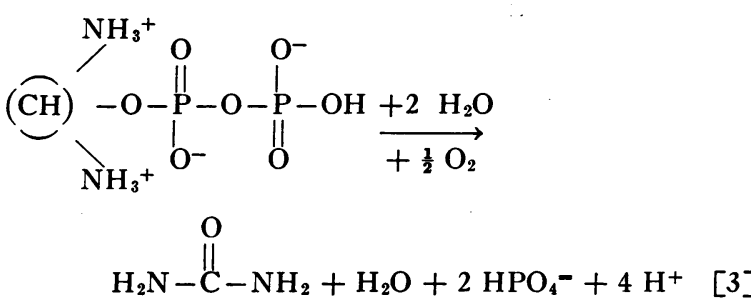

Orthophosphate diester

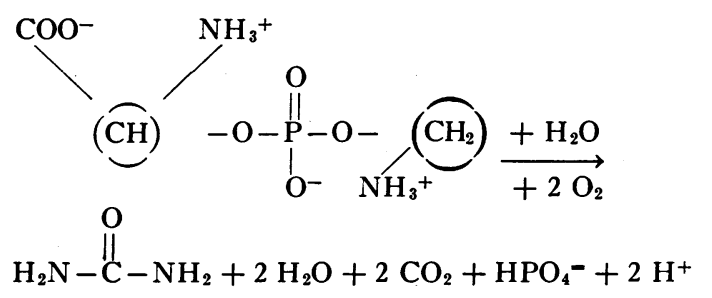

It can be seen that, regardless of the form in which phosphorus exists in the protein, the theoretical ratio of acid released to the phosphorus present is the same. The actual value of this ratio will depend upon the extent to which the secondary hydrogen is dissociated from phosphoric acid, and this in turn depends upon the $\mathrm{pH}$ of the medium in which these reactions take place. If the reactions are arbitrarily assumed to occur at $\mathrm{pH}$ $7.4,1.8 \mathrm{mEq}$ of acid would be released per mmole of phosphorus $\left(\mathrm{pK}_{2}^{\prime}\right.$ of phosphoric acid $=6.8$ ), but assumption of any other reasonable physiologic $\mathrm{pH}$ would not markedly alter this value. The actual mean ratio $(1.9 \pm 0.3)$ calculated from the four balances with J-protein is a reasonably satisfactory confirmation of this prediction.

In Figure 1, which shows the net external acid balance in one of the studies with J-protein loading, the significance of the acid contribution related to the soy phosphoprotein load is demonstrated. During the 3-day loading period, the distance between the heavy line indicating acid production and the dotted line parallel to it defines that part of the production derived from the extra phosphorus, assumed that this amounts to $1.8 \mathrm{mEq}$ per mmole of extra phosphorus fed. It is obvious from this figure that, if phosphorus had been neglected in the construction of the balance and if acid production had actually been at the level indicated by the dotted line, the net balance of acid would have remained approximately zero on the first two load- 
ing days and would then have become significantly negative on the third day. As a result there would have been an unexplained cumulative negative balance. With the phosphorus taken into consideration, however, the observed changes in net acid excretion fit into a physiologically more rational pattern, and the total acid excretion at the end of the study approximately equals the acid production.

Turning now to a consideration of the studies with meat, it is apparent from the data in Table III that there is no necessity to assume that acid is derived from the ingestion of extra organic phosphorus. Despite the fact that the amounts of beef fed contained more total phosphorus ( 55 to 100 mmoles) than did the load of soy protein (43 to 53 mmoles), there was no discrepancy between the total increment in measured acid excretion and the total increase in acid production calculated simply from the urinary inorganic sulfate and organic acids. As shown in Figure 2 it is possible to construct a satisfactory acid balance diagram without taking the extra phosphorus load into account. The acid retained during the loading period was virtually all excreted during the recovery period, and cumulative net balance at the end of the study was not significantly different from zero.

This difference between the acid production from the purified soy phosphoprotein and that from beefsteak indicates either that no acid is derived from the hydrolysis and metabolism of the phosphate residues in the meat and their associated cations, or that any acid arising from this source is neutralized by the generation of an equivalent amount of alkali during the metabolism of combustible anionic groups in the meat. If, for example, the phosphorus in the meat were mainly in the form of completely dissociated orthophosphate residues, neutralized by inorganic cations such as $\mathrm{K}^{+}$, no net acid would be released during metabolism, as illustrated in Equation 1. It would seem more likely, however, that acidogenic phosphodiester or pyrophosphate structures do exist in the meat protein or in the phospholipids of the meat, but their effect is balanced by the alkali derived from combustion of carboxyl groups neutralized by inorganic cations.

It should be noted that the ingested, rather than the excreted, phosphorus was used in the calculation of acid production. As pointed out previ- ously (1), the present balance technique assumes that body composition is relatively constant during the period of study, and in healthy subjects ingesting an adequate diet such an assumption seems reasonable. Theoretically, therefore, total excretion of phosphorus should equal intake, and either quantity should be suitable for the calculation of acid production. In the present studies, however. total urinary and fecal phosphorus differed from total intake, so that the apparent final cumulative balances varied from +79 to -93 mmoles, without any consistent difference between the studies with meat and with J-protein. The most likely explanation for the variability in apparent balance seems to be the inaccuracies inherent in the determination of fecal phosphorus when stools are scanty and the collection periods relatively short. Under these circumstances, phosphorus intake is clearly the proper basis for the calculation of acid production attributable to the metabolism of the J-protein.

The increased acid production from the J-protein averages $56 \mathrm{mEq}$ per $100 \mathrm{~g}$ of protein $(3.9 \mathrm{mEq}$ per $g$ nitrogen), compared with an increase of 10 mEq per $100 \mathrm{~g}$ of beef $(2.9 \mathrm{mEq}$ per $\mathrm{g}$ nitrogen $)$. Approximately two-thirds of the increase in acid production after meat feeding was accounted for by an increased urinary excretion of inorganic sulfate, whereas this accounted for only about onefifth of the increased acid from the soy protein load. All of the remaining increase in acid production due to the meat and an additional 17 to 33 per cent of the increased acid production due to soy protein was accounted for by an increase in the excretion of urinary organic acids. In one study of each type, serial measurements of urinary uric acid excretion revealed small increments during the loading periods of approximately 2 to $3 \mathrm{mEq}$ per day. Increased uric acid production would therefore account for no more than one-fifth of the total increase in organic acid. The identity of the remaining major fraction of the increment in organic acids remains undetermined, but it is clear that this increment could not be predicted on the basis of the known composition of the meat or soy protein. Since only the sulfur oxidized to sulfate generates endogenous acid, it is apparent that the acid accounted for by sulfur metabolism is also not strictly predictable from diet composition.

These considerations make it apparent that the 
net effect of protein metabolism on acid balance may be expected to vary considerably from one protein to another. The total amount of net acid released will depend upon: 1 ) the quantity and nature of the phosphate groups, 2) the relative proportion of combustible cationic and anionic groups (mainly $-\mathrm{NH}_{3}{ }^{+}$and $-\mathrm{COO}^{-}$, respectively), 3) the quantity of organic sulfur oxidized to sulfate, and 4) the net effect of the protein in augmenting organic acid production.

\section{SUMMARY AND CONCLUSIONS}

Large supplements of purified soy phosphoprotein and of beefsteak were fed to normal subjects and the effects on acid balance compared. The soy protein generated $3.9 \mathrm{mEq}$ of acid per $\mathrm{g}$ of nitrogen and the beefsteak $2.9 \mathrm{mEq}$ per $\mathrm{g}$ of nitrogen.

The results show that a significant fraction of the net endogenous acid produced from the metabolism of the soy protein was predictably related to its phosphorus content, but no such source of acid could be demonstrated from meat. It is suggested that the production of acid associated with the presence of phosphate groups in a protein will be determined by both the structural relationships of the phosphate and the nature of the associated cations.

The remainder of the acid production from the soy phosphoprotein and all of the acid arising from the meat was accounted for by increased oxidation of sulfur and increased endogenous production of organic acids.

\section{REFERENCES}

1. Relman, A. S., Lennon, E. J., and Lemann, J., Jr. Endogenous production of fixed acid and the measurement of the net balance of acid in normal subjects. J. clin. Invest. 1961, 40, 1621.

2. Lemann, J., Jr., and Relman, A. S. The relation of sulfur metabolism to acid-base balance and electrolyte excretion: The effects of DL-methionine in normal man. J. clin. Invest. 1959, 38, 2215.

3. Relman, A. S. Endogenous acid production and the measurement of the acid balance in health and disease. Honyman Gillespie Lecture, Univ. of Edinburgh, 1961. To be published.

4. Christensen, H. N. Diagnostic Biochemistry; Quantitative Distributions of Body Constituents and Their Physiological Interpretation. New York, Oxford Univ. Press, 1959.

5. Hunt, J. N. The influence of dietary sulphur on the urinary output of acid in man. Clin. Sci. 1956, 15, 119.

6. Perlmann, G. E. The nature of phosphorus linkages in phosphoproteins. Advanc. Protein Chem. 1955, $10,1$. 